\title{
A ENFERMAGEM COMO PRÁTICA SOCIAL
}

Ana Adelaide Martins*

\begin{abstract}
RESUMO - Este estudo baseou-se na Enfermagem como prática social e política, tendo como finalidade realizar um levantamento de visão do enfermeiro de Saúde Pública sobre sua prática.
\end{abstract}

ABSTRACT - This study performed on the basis of Nursing as a social and political practice, which goal is to effect a survey on the Public Health nurse's view of his/her practice.

\section{INTRODUC̣ÃO}

Nos vários documentos que propõem a implanta(cão de novas políticas de saúde mais adequadas às necessidades da população, surge sempre a questão da desatualização dos profissionais de saúde, com sua formação quase que estritamente biológica, voltada prioritariamente para o indivíduo, sem lhe dar as bases necessárias para compreender e trabalhar a nível social.

Através de sua evolução histórica a Enfermagem tem-se proposto a atender às necessidades básicas do ser humano; afetadas pelos vários processos patológicos. Tem conquistado o seu espaço, afirmado a sua utilidade, justificado sua prática através desse propósito. Para realizá-lo, tem aprof undado seus conhecimentos científicos, aprimorado sua técnica, buscado definirse e estabelecer sua estrutura, delinear seu perfil, compreender-se como profissão. Numa abrangência cada vez maior de visão e conceitos, ela se vê agora diante do ser humano social e culturalmente determinado, impossível de ser entendido isoladamente. As práticas que visam atender às necessidades básicas af etadas do ser humana já não podem mais se restringir a curar o indivíduo para devolvê-lo ao meio insalubre que tem afetado agressivamente todas as suas necessidades de sobrevivência. A visão alargada do ser humano mostrou a relatividade do individual frente ao social. As doenças, cujos índices são alarmantes, são a desnutrição, o desabrigo e suas conseqüências. As suas causas não estão no indivíduo isolado nem dependem dele, nas forças que as determinam. As graves patologias sociais do presente então a exigir uma enfermagem capaz de se entender e se localizar como prática social (e se rees- truturar teórica e praticamente para isso) ou uma nova definição de propósitos, talvez menos ambiçiosos e abrangentes.

A importãncia de levantar o assunto, debatê-lo e clarificá-lo, não se restringe à enfermagem apenas, mas a todos os setores dos serviços de saúde como demonstram as conclusões dos organismos mundiais, principalmente a OMS e os vários estudos locais. A aplicabilidade dessas conclusões parecem depender da capacitação dos profissionais que atuam dentro de situações específicas de cada país ou região. Essa capacitação deve fazer dele um profissional capaz de realizar a síntese entre o todo e suas partes - entre o social e o biológico. Este trabalho teve como finalidade fazer um levantamento da visão do enfermeiro de Saúde Pública sobre sua prática. Esclarecer com que nível de consciência social o enfermeiro de saúde pública se define; como ele está formando essa consciência social; para quais propósitos ela o está levando.

Responder a essas questões colocará o enfemeiro mais próximo de uma auto-compreensão e deverá ajudá-lo a reafirmar ou a redefinir os seus propósitos. Estes determinarão as características que a enfermagem assumirá frente aos desafios do presente e projetarão sua imagem no futuro.

\section{OBJETIVOS}

Foram os seguintes os objetivos desta pesquisa:

2.1 Detectar o conceito de saúde pública percebido pelos enfermeiros de Saúde Pública.

* Enfermeira, Professora Auxiliar da Escola de Enfermagem da U.F.M.G. 
2.2 Analisar a visão do enfermeiro de Saúde Pública sobre a utilidade e alcance de sua prática profissional no contexto sócio-político-econômico.

2.3 Verificar os fatores que interferem na formação das concepções do enfermeiro de Saúde Pública sobre o seu trabalho.

2.4 Levantar propostas alternativas para a formação e a atuação do enfermeiro de Saúde Pública coerentes com as reais necessidades de saúde da população.

\section{METODOLOGIA}

O universo da presente pesquisa constou de quarenta e sete unidades pertencentes tanto ao Centro Metropolitano de Saúde (Secretaria Estadual DEMG) como à Secretaria Municipal de Saúde, inclusive suas sedes, onde atuavam, em janeiro de 1984 (quando se realizou o levantamento preliminar) um ou mais enfermeiros totalizando noventa e seis profissionais, dos quais se selecionou uma amostra pelo método aleatório.

O instrumento utilizado foi um questionário, acompanhado de uma carta de apresentação da pesquisa. Este foi elaborado, testado e aplicado, segundo os objetivos propostos. Dos oitenta questionários distribuídos, foram devolvidos 23 (cerca de $28 \%$ ), um dos quais totalmente em branco. Foi feita então a tabulação dos dados numéricos, a classificação e organização das questões não numéricas, partindo-se para a fase de análise. Finalmente foi feita a redação definitiva, da qual algumas partes foram completamente retiradas, outra sintetizadas, para a atual apresentação.

\section{MARCOS TEÓRICOS}

Este trabalho se baseia nas teorias de determinação econômica da estrutura social (GEBRAN, 1978), que, para as formações sociais caracterizadas, de um lado, pela posse dos meios de produção e, do outro, pela venda da força de trabalho. Esta dicotomia, em razão dos interesses específicos de cada classe, se configura na exploração e dominação de uma classe sobre a outra. Historicamente a classe que exerce a dominação tem sido aquela que possui os meio de produção. Para isso se utiliza de um poder coercitivo e uma força ideológica, representados pelo aparato do Estado e pela hegemonia. A resistência da classe dominada à exploração e a def esa dos seus interesses próprios, leva ao antagonismo, que se configura nas lutas entre as classes, à existência de forças sociais que se contrapõem e que estabelecem a dinâmica que elabora a história.

A transposição do modelo do Modo de Produção Capitalista para uma formação social concreta deve levar em conta as especificidades dessa sociedade, sua própria história, seu momento conjuntural específico.
No atual momento histórico deve levar também em conta o aumento consistente do setor terciário nas economias capitalistas, as possíveis conseqüências de situações como a automação dos setores produtivos e o papel intervencionalista do Estado na manutenção do equilibrio das forças sociais. No momento em que o enfermeiro busca definir seu papel social, ele deve buscar compreender o lugar que ocupa, as possibilidades e limitações que a estrutura social lhe impõe. Esta teoria, por ser a que melhor explica os mecanismos sociais de dominação/subordinação, ajuda o enfermeiro a compreender a dialética das instituições onde ele atua, e no desmascaramento das ideologias dominadoras. Ajuda-o também a comprometer-se com a valorização da resistência das classes populares e com a mudança intra-estrutural das instituições prestadoras de serviço de saúde no país. Poderá levá-lo, portanto, a uma ação política objetiva e conseqüente.

Como subsídio para uma análise das características dos grupos prioritários para a atenção de saúde foram utilizados os estudos sobre a distãncia cultural que se estabelece entre os migrantes de "primeira geração", que se localizam nas periferias das grandes cidades e os indivíduos de origem urbana (SEGUNDO, 1978). Aqueles, trazendo uma bagagem existencial fundamentalmente ruralista, necessitam aprender a usar e a manipular os mecanismos que movem as grandes cidades: suas exigências de trabalho, seus meios de transporte, sua of erta de bens e serviços. Sentem-se "perdidos" no mundo dos documentos, da escrita, do valor monetário, da moral abrangente das sociedades abertas. 0 problema migratório, no Brasil, não é apenas a evasão de recursos humanos do campo, mas uma concentração de pessoas inadaptadas aos mecanismos sociais das grandes cidades. Suas dificuldades não podem ser superadas apenas com informações que visem a substituição de hábitos culturais. Tais pessoas precisam ser habilitadas a utilizar os mecanismos novos que não aprenderam ainda a manipular a fim de ter garantidas suas possibilidades de sobrevivência e de conquistar uma integral maneira de viver, mas isto transcende os objetivos dos serviços de saúde.

As dificuldades do enfermeiro no desempenho de suas funções como agente social se ligam aos mecanismos alienantes que envolvem tanto a sua formação profissional como sua prática diária. A alienação impede a visão globalizada da sociedade e prende o profissional às distorções encontradas na prática, tornando-o profissionalmente frustrado. Esta é a hipótese que a presente pesquisa se propõe a conferir.

\section{CARACTERISTICAS DA AMOSTRA}

Os Enfermeiros de Saúde Pública de Belo Horizonte, que responderam ao questionário constituem uma 
amostra cuja qualidade pode ser avaliada pelas seguintes características:

5.1 Sexo: 95\% foram do sexo feminino, correspondendo a uma situação de normalidade na Enfermagem, profissão notoriamente exercida por mulheres.

5.2 Idade; a totalidade dos respondentes situou-se entre os 20 e os 45 anos, estando o maior número localizado na faixa de 31 a 35 anos.

5.3 Local de Trabalho: as indagações sobre o local de trabalho evidenciaram que as instituições que normalmente contratam os serviços do Enfermeiro de Saúde Pública em Belo Horizonte, a Secretaria Estadual de Saúde e a Secretaria Municipal de Saúde, estavam quase que igualmente representadas na amostra, havendo um predomínio de $10 \%$ da Secretaria Estadual, o que parece razoável, uma vez que o número de Enfermeiros trabalhando naquela instituição era ligeiramente maior, na época do levantamento.

5.4 Cargo que Ocupam: 60\% são enfermeiros que atuam a nível local, ficando os restantes $40 \%$ divididos entre os cargos de supervisão, assessoria, normatização e ensino, mais ligado ao nível central.

5.5 Tempo de Trabalho: quanto ao tempo de experiência no trabalho verifica-se que mais da metade tem de 3 a 5 anos de serviço, configurando um profissional experiente e conhecedor de suas funções.

5.6 Órgão Formador: as instituições de ensino onde estes profissionais se formaram foram, em sua quase totalidade, as duas Universidades de Belo Horizonte que oferecem o Curso de Enfermagem, a PUC e a UFMG, esta com o dobro do número daquela. Apenas um citou a USP, demonstrando que, em geral, o enfermeiro permanece no Estado onde se forma, mas principalmente regionalizando a problemática da formação do Enfermeiro levantada neste trabalho.

5.7 Tempo de Formado: Uma retrospectiva histórica dos problemas da Universidade brasileira tem mostrado que a partir de 1964, em razão da conjuntura ditatorial e repressiva que então se impôs no país, a Universidade foi colocada à margem não apenas das decisões econômicas, mas de todas as decisões políticas que deveriam interessá-la, perdendo totalmente prestígio e hegemonia através de vários mecanismos. Tais são o exilamento de intelectuais, o esmagamento financeiro dos órgãos de representação estudantis, "reforma universitária", etc. As conseqüências, várias e graves, incluiram o controle ideológico da Universidade e a queda da qualidade do ensino, surgindo um período de "profissionalismo" tecnicista e alienado, que chega ao seu apogeu quando, em 1975, a crise do pretróleo faz ruir o "milagre brasileiro" e leva ao caos a economia nacional. Todo o sistema passa então a ser questionado e já se mostra mesmo inviávesl sofrendo pressões que acabam levando à "abertura". Esta permite o retorno dos intelectuais exilados e reforça alguns focos de resistência ideológica que ainda restaram dentro das Universidades. Já no final da década de 70, o ensino começa a denunciar os ef eitos danosos do capitalismo selvagem implantado em nosso país, com suas perversas conseqüências para a população. Pelas respostas dadas ao questionário pode-se perceber que mais de 80\% dos Enfermeiros de Saúde Pública que estão trabalhando em Belo Horizonte se formaram após 1976, sendo que $16 \%$ o fizeram após 1980. Entretanto, uma das características históricas da Enfermagem é o conservadorismo, o que torna lenta a incorporação de novas idéias para a categoria. Isso quer dizer que, muito provavelmente, o ensino de Enfermagem nesse período ainda conservava as características do período repressivo, mas podendo, num dado momento, aparecer em alguns focos de resistência ideológica, ainda que esparsos.

Como apenas $12 \%$ dos Enfermeiros constantes da coleta têm mais de 10 anos de formados, é provável que a amostra retrate com bastante fidelidade a situação atual dos enfermeiros de Saúde Pública de Belo Horizonte.

5.8 Formação Específica; dos vinte e dois respondentes, dez fizeram o curso de Habilitação em Saúde Pública, sete fizeram o Curso de Especialização em Saúde Pública, quatro fizeram ambos os Cursos e um informou Habilitação em Médico-Cirúrgica. Observa-se pois, que o Enfermeiro tem buscado no sistema oficial de ensino a bagagem de formação que este sistema pode lhe oferecer.

5.9 Outros Cursos: quanto a cursos de reciclagem contínua, grupos de estudo e discussão, encontros e correlatos, as respostas sugerem que o profissional Enfermeiro, terminada sua formação específica, só busca atualizar-se em função exclusivamente das necessidades do serviço, através do treinamento, of erecido pelo próprio serviço. A educação continuada, a atualização científica, a discussão dos problemas enfrentados pela categoria, etc., parece ser preocupação de apenas uma minoria.

\section{CONCEITO E OBJETIVOS DOS SERVICOS DE SAÚdE PÚBLICA PERCEBIDOS PELOS ENFERMEIROS}

Conceitos são representações abstratas da realidade por meio das suas características gerais. Essa "caracterização" da realidade "serviços de saúde" com- 
porta um nível "prático"de como ela é vista e sentida pelo profissional e um nível "ideal", o do discurso com que as instituições justificam sua atividade. Historicamente os dois níveis têm sido diacrõnicos, uma vez que o nível da prática pertence à dimensão econõmica $\mathrm{e}$ o discurso pertence à ideologia. A ideologia com que as classes hegemõnicas justificam os serviços de saúde, no Brasil, é extremamente carregada de valores idealistas e objetivos éticos. Assim se usam expressões como "bem-estar social", "bem comum", "promoção", "proteção e recuperação da saúde", " melhoria das condições de vida da população", e muitas outras, variando um pouco tais expressões em decorrência do instante conjuntural. Atualmente, por exemplo, foi acrescido um amplo rol dessas expressões como "equidade", "universalização", "controle democrático", qualidade de vida", etc, etc. Tais conceitosideológicos, eticamente desejáveis, no entanto, permanecem como pura retórica. Seu objetivo é tornar socialmente aceitáveis as ambíguas práticas político-econõmicas que encobrem.

Para REZENDE "o trabalhador intelectual absorve, juntamente com a qualificação técnico-científica realizada na Universidade, os valores inculcados pela violência simbólica". Aliás, tais valores lhe são inculcados em todas as isntãncias de seu cotidiano, e são permanentemente introjetados, constituindo-se numa espécie de "superego" social, que só pode ser superado a nível de consciência reflexiva, num processo constante de análise da realidade e desmistificação desses valores.

Assim, ao longo de sua vida profissional, duas possibilidades se of erecem ao enfermeiro: a de imergir no contexto, alienar-se, adaptar-se ao papel que o sistema lhe atribui ou a de procurar objetivar suas condições de trabalho, inserindo-as no contexto social, explicando-as historicamente e buscando, na reflexão, os caminhos para a transformação daquilo que impede a maior humanização do mundo, que a prática profissional deve servir (FREIRE, 1979).

A indagação de "como você conceitua Saúde Pública a partir de sau experiência profissional", três não responderam, equivalendo esse número a $13,0 \%$ do total de respondentes.

Quanto às respostas obtidas o que se percebe é que não existe muita clareza a respeito de um conceito de Saúde Pública. De um modo geral os conceitos expressam e refletem o discurso hegemõnico indicando uma certa ausência de criticidade ou seja, uma certa ingenuidade de visão, como por exemplo:

- "É um veículo usado para alcançar melhores níveis de saúde da população ou para manter os níveis condizentes já alcançados".

- "É uma parte da área de saúde que visa atender as necessidades de uma comunidade. É de suma importância que esse atendimento seja preventivo e curativo". Etc.
Alguns a conceituaram por aquilo que desejariam que ela fosse:

- "É o campo de atuação da saúde que deveria produzir serviços de saúde a fim de promover, proteger, prevenir e recuperar a saúde da comunidade". — "É um trabalho junto à comunidades ou grupos da comunidade, que tem como fator básico a educação, a orientação e a discussão das questões de saúde da população".

Percebe-se assim que a grande maioria das respostas $(13+3)$ não inclui qualquer referência ao papel controlador dos serviços de saúde à sua importância política na estratégia de hegemonia, nem mesmo parece traduzir um conceito refletido e amadurecido na prática que o profissional desenvolve, limitando-se a repetir o discurso ideológico ou a listar as tarefas executadas como se elas consituissem um fim em si mesmas. Os conceitos restantes já denotam uma certa percepção que transcende o discurso e aponta a ambiguidade da prática, ainda que não fique totalmente claro, na verbalização, até onde essa percepção consegue alcançar. Por exemplo:

- "Conjunto de ações preventivas e curativas simplificadas, colocadas à disposição principalmente da população de baixa renda, ações estas de resolutividade muito pequena, uma vez que não atingem o cerne da questâo que é, fundamentalmente, sócio-econômica".

- "Transmitir à população que através da luta em grupo eles conseguirão melhores condições de vida e saúde".

Aliás, a dificuldade de expressão verbal perpassa a grande maioria das respostas. A pouca clareza na verbalização, compreensível numa formação alienante e alienada aponta para as deficiências dos organismos de formação intelectual e técnica, as escolas, também elas reprodutoras das ideologias que interessam à classe hegemõnica.

Vê-se que os conceitos de Saúde Pública nem sequer indicam uma verdadeira visão sanitarista, estando esta reduzida a um atendimento individualizado de baixo custo, destinado à populaçâo de baixa renda. Isto, certamente, reflete a realidade desses serviços no desempenho de seu papel "compensador" - "equilibrador" dos desníveis sociais e, portanto, "controlador" que não parece ter sido alcançado ainda pela maioria dos profissionais de saúde, mas que não ficou de todo ausente nas respostas.

À indagação: "Este conceito é aplicável à situação real dos serviços de saúde ou à indagação ideal?" obteve-se os seguintes resultados: 10 responderam que à situação ideal, correspondendo a 45,5\% das respostas; 07 responderam que à situação real $(31,8 \%)$; 01 respondeu que ambas $(4,69)$ e 04 nã̃o responderam à questão $(18,1 \%)$.

Apesar de se ter pedido um conceito baseado na prática profissional, a grande maioria apresentou um 
conceito que considerou "desejável" ou referente a uma "situação ideal". Como tais conceitos relfetem, por si mesmos, alienação e falta de clareza, a resposta atual reforça a análise anterior.

\section{- Os objetivos dos Serviços da Saúde Pública}

Os serviços de Saúde Pública apareceram na Europa quando, em decorrência das péssimas condições de vida do operário na fase de implantação capitalista, proliferam as doenças de massa que roubam mãode-obra do mercado de trabalho e colocam em risco as próprias classes dominantes. Antes disso, já a ideologia mercantilista defendia as vantagens econômicas do controle social das doenças, como fator de fortalecimento do Estado. Mas é a lógica da acumulação que leva à aprovação da Poor Law, na Inglaterra de CHADWICK e outras medidas semelhantes, na Alemanha de SAKENDORF (CAMPOS, s.d). No Brasil, os fatos se repetem: a história da Saúde Pública neste país é a história da implantação e desenvolvimento do sistema capitalista gerando pressões a que os serviços de saúde são a resposta, destinada a aliviar as tensões sem mudar as estruturas de produção, perpetuando as relações sociais, os sistemas de privilégios, as classes diferenciadas à luz da História, vistos em seu contexto, os serviços de saúde aparecem como uma específica estratégia da hegemonia, quando as forças sociais que predominam num dado momento ameaçam romper a base econômica que sustenta o capitalismo, sistema em permanente conflito de interesses sociais derivados dos antagonismos entre as classes.

A par de uma permanente veiculação ideológica que implante ideiais de acumulação econômica como aspirações éticas, valorize como únicos válidos, os símbolos da acumulação e, logicamente, faça rejeitar aqueles que não se prestem a tal fim. Mantenha, afinal, as classes dominadas submissas e "adaptadas" ao seu status, funcionando como um verdadeiro mecanismo de controle social. O discurso hegemônico não visa revelar esses objetivos,mas encobrí-los, mascará-los, tornálos facilmente assimiláveis e desejáveis. Mas para que a realidade que o discurso encobre não seja percebida, é necessário que aqueles a quem ela se destina não sejam capazes de ter uma visão globalizada do processo. Eles devem ser mantidos alienados, percebendo apenas aquela parte do todo que lhes permita atuar para os fins específicos do processo, em "estreitos especialismos" (FREIRE, 1979) nas funções para as quais o sistema os emprega.

Esta situação dos serviços de saúde não está muito distante no tempo, realizando-se, aqui e agora e as Ações Integradas de Saúde são um exemplo bem atual. No momento em que o Sistema Nacional de Saúde entra em falência, duas possibilidades se abrem apra o impasse: A proposta dos políticos de tendência socialista que, reconhecendo que o sistema de saúde se insere num mais amplo contexto nacional, defendem o Sistema Unificado de Saúde (SAÚDE, 1985) integrado a um projeto de mudanças sociais e econômicas que envolvam todos os setores da Nação, dando espaço à participação popular, única força capaz de legitimar as reformas preconizadas. A outra possibilidade é o plano de Reorientação da Assistência de Saúde no Âmbito da Previdência Social (BRASIL, 1982), proposto pelo CONASP e que é em última análise uma forma de administrar a crise através de dois procedimentos simples: a "socialização" dos prejuízos e uma nova modalidade de gerenciamento. Radicalmente diferentes as duas propostas, seja quanto à origem, seja quanto ao modelo proposto, seja quanto ao nível de mudanças pretendido, ambas trazem no seu discurso os mesmos slogans, os mesmos "princípios básicos" como reconhecimento da saúde como direito de cidadania e, portanto, dever do Estado. No momento em que as praças se esvaziam das reivindicações populares, também se esvazia a idéia de um sistema único de saúde. E, apesar de não haver nenhuma relação entre as duas propostas (a não ser uma progressão semântica entre integrado e unificado) as AIS passa a "encarnar" a estratégia para chegar a Unificação, que jamais foi cogitada no Plano do CONASP por ferir as possibilidades de sobrevivência das forças representadas por aquele órgão. É assim que o sistema unificado é "apropriado" e deixa de existir como possibilidade autônoma. Este é o mecanismo de conservação bastante usual empregado pela hegemonia em suas manobras de sobrevivência.

As perguntas 10 e 11 foram, respectivamente; "Na sua opinião quais são os objetivos dos nossos serviços de Saúde Pública" e "Em que medida esses objetivos são alcançados", com as seguintes opções: integralmente alcançados, em parte alcançados e não alcançados.

Dez respostas dadas apenas repetem os slogans do discurso hegemônico, sem qualquer sinal de criticidade, como por exemplo:

- "Melhorar o nível de saúde da população. Em parte alcançados".

- "Proteger, Prevenir, Promover - Recuperar a Saúde. Em parte alcançados".

As dez seguintes elaboram uma lista dos objetivos praticamente vistos, algumas mantendo slogans, mas já apontando algumas contradições percebidas, como por exemplo:

- "Atender (assistência médica) à população carente. Em parte alcançados".

- "Oferecer aos profissionais de saúde mercado de trabalho. Vender serviços ao INAMPS. Oferecer $80 \%$ de resolutividade em assistência à doença no primeiro nível de atendimento (ambulatório geral). Servir à comunidade da melhor forma possível. Em parte alcançados".

- "Na realidade, na prática: uma assistência mínima à população "marginalizada" do processo de produção, que garanta, pelo menos a sobrevivência do cor- 
po físico. Tanto que os serviços são de baixa qualidade e, após o PA cobra-se produtividade; a qualidade fica em segundo plano. Em parte alcançados, considerando os objetivos ideais".

Pode-se objetar à colocação da resposta que o objetivo dos serviços não é a sobrevivência de pessoas, mas do sistema capitalista, ao qual o corpo físico só interessa como força de trabalho. A faixa "marginalizada" é uma força excedente, que o sistema não pode incorporar, é uma "sobra" que inclusive não pode crescer demasiado para não gerar tensões que o sistema não possa resolver.

Estas 20 respostas afirmam que os objetivos expostos são "em parte alcançados" e, uma vez que os objetivos que afloraram foram os ambigüos ou contraditórios (como o próprio sistema), traduzindo pouca criticidade e reflexão, provavelmente o resultado não poderia ser diferente.

As duas respostas restantes afirmam que os objetivos não são alcançados e assim os explicitara:

- "Proteção à saúde (controle de D.T., imunizações, etc) - Manutenção da saúde (Materno-Infantil, mental, nutrição, educação sanitária) - Recuperação da saúde (atendimento médico, estritamente, hospital, ambulatório). Proteção social - 0 meio controlado (saneamento básico, poluição, habitação, etc." - Não alcançados.

- "Melhorar as condições de reivindicação da população - Saúde Preventiva". - Não alcançados.

A primeira reconhece que os objetivos que os serviços se propõem explicitamente a prestar, na realidade não o são; a segunda faz a mesma afirmativa com relação àqueles objetivos que o enfermeiro deveria perseguir. Fica claro que o único objetivo integralmente alcançado é o controle social e a preservação do sistema. A pergunta seguinte tenta aclarar melhor o que se pretende com relação aos objetivos dos serviços, com a seguinte indagação: "Você acha que existem objetivos diferentes daqueles que são explicitados nos programas de Saúde Pública? Quais você identifica?"

A esta questão 06 pessoas não responderam e uma colocou, apenas, "sim" - o que dá cerca de $35 \%$ de respostas que, ou não chegaram sequer a compreender a pergunta, ou consideraram completa e acabada a resposta anterior reforçando a análise.

Três pessoas colocaram que estes objetivos eram "políticos", sendo que duas não explicitaram nada: - "Sim. Político".

- "Projeção política (contratação de pessoas não capacitadas em saúde-doença)".

Duas pessoas aprovaram os objetivos explícitos e colocaram a falha na operacionalização.

- "Os objetivos explictados nos programas são abrangentes, o problema está na operacionalização."

- "Considero os objetivos escritos e propostos muito bons, porém não são reais na prática. Outros objetivos virão a surgir, mas apenas num segundo momen- to ou outra sociedade. Vejo o papel da Saúde Pública como todo coordenador de ações de saúde no meio da comunidade, da população. Mas quando?..." Uma vez que é exigência do processo que os objetivos explícitos não sejam reais e os objetivos reais não sejam explícitos, certamente que o fato daqueles serem "bons" não os torna mais operativos, mesmo que contem com a aprovação social geral.

Uma lembrou o papel de "cata-lixos" dos serviços de saúde:

- "Atenção às doenças degenerativas e mental-psicossomáticas, que são produtos do capitalismo".

Esse é um dos mais "simpáticos" papéis dos serviços de saúde dentro do sistema capitalista: darem destinação ao refugo humano "inadaptado" ao sistema de produção ou exaurido do processo. É claro que quem gera o "lixo", deve providenciar o "cata-lixo", ou "entulho" pode obstruir o sistema.

- “Sim. Após 1964 a Saúde Pública tem sido uma ten-

tativa, embora completamente distorcida, de redistribuição de renda. Percebe-se claramente que, se o trabalhador pudesse usar o dinheiro que lhe é descontado para serviços médicos, seria bem melhor atendido. E, como já disse anteriormente, uma forma de conter a tensão social".

Se a afirmação está correta, deve-se explicar para quem a renda estava sendo redistribuída, uma vez que esse período marcou o início da completa falência financeira das instituições de saúde no Brasil. 0 que se percebe claramente é que o trabalhador mantém, compulsoriamente, o sistema, mas não participa das decisões que promovem o "retorno".

Algumas respostas não falaram propriamente de objetivos, ou apenas repetiram-se.

Duas respostas reconhecem um ou mais dos objetivos não explícitos dos serviços de saúde no sistema capitalista, ou, pelo menos, reconhecem o mecanismo que os determina:

- "Sim. O objetivo não explicitado da contenção social".

- "Válvula de escape" para diminuição das tensões sociais, discriminação dos serviços: saúde pública para o pobre e seguro saúde para o rico; ampliação do "controle da natalidade"; consulta médica para a mulher enquanto matriz".

0 questionário mostra que quatro pessoas, em 22 (ou seja, mais ou menos $20 \%$ ) entre especialistas e habilitados em Saúde Pública, trabalhando, já por um tempo razoável nos serviços onde atuam, sendo que o restante (cerca de $80 \%$ ) provavelmente está sendo utilizado ingenuamente na reprodução do sistema de dominação em vigor.

\section{- A Atuação Política do Enfermeiro}

A pergunta n? 8 foi: "Você acha que a atuação do 
Enfermeiro é: - Política - Técnica-Social", com os seguintes resultados:

Política -02 respostas; Técnica -07 respostas; Técnica e Social - 01 resposta; Política, Técnica e Social -12 respostas.

Observa-se que 07 pessoas colocaram a atividade do Enfermeiro de Saúde Pública como apenas "técnica" e como "técnica e social", negando a dimensão política dessa atuação. A seguir são citados alguns exemplos:

- "Técnica. O Enfermeiro ainda não está voltado para o político e o social".

- "Técnica. 0 Enfermeiro atua dando assistência principalmente ao indivíduo doente".

- "Com inúmeras dificuldades nesta área. etc.

- "Técnica e Social". Técnica quando se faz reorganização do serviço, treinamento de pessoal auxiliar, supervisão técnica de Enfermagem. Social, quando influencia comportamentos através de promoção de saúde e grupos de pessoas".

Estas explicações colocam o componente político da ação na "intencionalidade" ou no "preparo do enfermeiro", ou mesmo nem chegam a questionar a "neutralidade" política reproduzindo o velho discurso de tecno-burocracia. Entretanto, existindo como componente dinãmico de um sistema de saúde com objetivos sociais específicos, estruturado, direcionado e controlado por uma política de saúde, qualquer atuação desse componente é também política, devendo alcançar os fins sociais propostos. Isto é, se o agende de saúde, no caso, o enfermeiro atua em seu posto de saúde apenas dando assistência ao indivíduo, ele está concorrendo para o alcance dos objetivos de manutenção do statu quo quer esteja ou não presente o componente pessoal da "intencionalidade". Isto tem uma conotação política especificamente conservadora. 0 conservadorismo não é necessáriamente "não intencional" (certamente não o é para as classes hegemônicas). Mas a ausência de intencionalidade no alcance dos resultados que a ação profissional visa obter configura a "ingenuidade" do profissional que o sistema manipula, sem que ele o perceba.

Também na mesma linha de raciocínio, não é o maior preparo que vai dar ao enfermeiro condições de agir politicamente, já que ele o estará fazendo, preparado ou não para isso. 0 "preparo" poderá é dar-lhe condições de agir intencionalmente, isto é, substituir sua visão ingênua por uma visão crítica. Preparo e intenção poderão fazê-lo "mudar de política", se os objetivos desejados forem outros.

Duas respostas colocaram que a atuação é apenas política, explicando:

- "Política. A atuação é sempre política, mesmo que não consciente. $O$ profissional, antes de ser enfermeiro é um cidadão e, como tal, atual politicamente".

- "Política. Visa cura e não prevenção; o atendimen- to deve ser dado à quantidade e não por qualidade; trabalha com uma equipe auxiliar sem o devido preparo para o desempenho da função e até sem condição para assimilar o que é ensinado". A palavra "política" na última resposta tem sentido claramente pejorativo, ou é apenas a velha dificuldade de verbalização do enfermeiro?

As 12 respostas seguintes classificam a atuação do enfermeiro como: política, técnica e social, e explicam, por exemplo:

- "Técnica, devido às atividades desenvolvidas pela enfermeira junto à clientela e também devido às atividades desenvolvidas junto aos auxiliares de saúde (reciclagem, treinamento, etc.). Os problemas sociais, políticos e financeiros af etam diretamente a saúde de uma população. Os enfermeiros de Saúde Pública, exercendo um trabalho junto à comunidade, não deixam de ter uma atenção política e social sobre ela".

- "Acho que é inevitável separar os aspectos acima citados da atuação de qualquer que seja o profissional. No entanto, é evidente que a atuação política e social do enfermeiro de Saúde Pública se encontra sufocada pela sua atuação técnica, determinada pela fragilidade que tem sido própria da nossa categoria (generalizando)".

- "O Enfermeiro, como qualquer outro profissional de saúde está inserido no contexto social e político do país e suas funções técnicas são integradas com políticas vigentes".

Nem sempre a resposta consegue ser coerente, na explicação das três dimensões da atuação do enfermeiro. Dimensões estas que só estão artificialmente separadas e não o podem ser, na realidade. Aliás a pergunta teve objetivo de observar se o enfermeiro negava a "politicidade" de sua atuação e se era capaz de explicitá-la, demonstrando assim já ter superado o mito da "neutralidade política do técnico". Uma vez que se perceba que a escolha da técnica é também uma opção política, que técnica e política se realizam no meio social onde têm uma destinação específica, essa divisão mostra-se impossível. Entretanto, essa "indivisibilidade" dos três aspectos da atuação profissional ficou clara em apenas pouquíssimas respostas. A grande maioria ou apenas reafirmou a tridimensionalidade da atuação, sem explicitá-la ou separou cada uma delas em compartimentos estanques: é técnica quando faz isso, é política quando faz aquilo, etc. Esta visão é quase tão "ingênua" quanto aquela que nega a "politicidade" da atuação.

\section{- A Influência Econômica}

À indagação de: "Você acha que o sistema econômico brasileiro afeta o serviço de saúde onde você trabalha e, consequentemente, o seu próprio trabalho? obteve-se totalidade das respostas positivas. 
Ainda que a totalidade dos entrevistados tenha respondido afirmativamente, existe uma certa diferença quanto ao modo de ver como o sistema econômico af eta $o$ trabalho do enfermeiro. Assim alguns atribuem a influência do setor econômico af eta o trabalho do enfermeiro. Assim alguns atribuem a influência do setor econômico à pouca destinação de verbas para a saúde o que traduziria a não priorização atribuída aos serviços de saúde; outros colocam essa influência na distribuição diferenciada da renda, obrigando a grande maioria da população brasileira a viver sem a mínima "condição de sanidade", houve mesmo quem atribuísse tal influência à dependência de mais e mais verbas para se aplicar a técnica.

O que transparece de todas as respostas é a certeza de que o sistema econômico af eta a prática profissional e não está afetando positivamente, mas de maneira estranguladora, tanto para a clientela como para o serviço.

De um modo geral, aqueles que se fixaram nas deficiências do serviço, na má qualidade do atendimento, na sotisficação da técnica, na ingerência dos serviços de saúde, na não-priorização dos setores sociais como saúde e educação, etc., trocaram os ef eitos pela causa. Não conseguiram, portanto, passar além dos ef eitos superficiais, ainda que danosos, da determinação econômica do capitalismo, que se baseia na distribuição diferenciada da renda nacional, condenando grandes massas populacionais a condição de miserabilidade que nenhum serviço de saúde, por mais eficiente e bem estruturado que seja, pode "curar".

Entretanto, cumpre lembrar que, apesar do sistema econômico determinar e direcionar toda a dinâmica social onde se inserem os serviços de saúde e ser, portanto, a causa última de suas contradições, isto está encoberto por toda uma série de processos mascaradores que diluem a compreensão, voltando-a para os ef eitos que, por estarem mais diretamente ligados ao profissional de saúde, são percebidos por estes como "causadores da inoperância" desses serviços e das "frustrações" do profissional.

\section{7. $O$ INDIVIDUAL E O COLETIVO NOS SERVIC̣OS DE SAÚDE PÚBLICA.}

\section{- 0 alcance social dos Serviços de Saúde}

À indagaçâo de: "O atendimento de Saúde Pública de Belo Horizonte, na prática, afeta o indivíduo ou a comunidade?" - obteve-se 16 respostas para "o indivíduo"; 03 para "A comunidade"; 02 para "ambos"; e 01 nâo respondeu.

Esse resultado vem reafirmar que, na visâo do enfermeiro de Saúde Pública, o alcance desses serviços é apenas individual. Isto é, estes serviços se limitam a um atendimento individualizado de baixo custo, destinado à população de baixa renda, não relacionado, necessariamente, a uma visão "sanitarista", ou, poderse-ia dizer "epidemiológica" das condições de sanidade de uma comunidade. Esta é uma visão "realista" da situação dos serviços onde o enfermeiro está inserido e, pelo menos a grande maioria, pode percebê-lo.

Os Serviços de Saúde têm sof rido, historicamente em nosso país, a dicotomização permanente entre "curativos" e "preventivos"; "individuais" e "coletivos"; "particulares" (ou "privados") e "públicos" - e toda tentativa de unificação esbarra nas potentes forças dos interesses antagõnicos que tal divisão carrega. De um modo geral a medicina, no Brasil, é eminentemente privativista, curativa e individualizada, refletindo de maneira incontestável, o sucesso com que as classes hegemônicas têm manipulado a doença e os anseios de sanidade da população.

A partir de um período histórico em que a medicina privada era exercida pelo médico da família, sem qualquer mediação entre o médico e o paciente, o sistema econômico vai extendendo seu domínio no campo da saúde, principalmente através do controle ideológico da classe médica. Esta classe tem sido, neste país, historicamente "capitalista". 0 "médico da familia" era sempre o dono de uma ou mais "fazendas", ou do hospital, farmácias, etc., numa história que não está tão distante assim. Por isso esta classe profissional foi tão facilmente convertida em mantenedora e reprodutora das condições mais favoráveis para a verdadeira apropriação capitalista da medicina, que hoje se concretiza nos grandes complexos médico-hospitalares, nos sofisticados laboratórios, nas indústrias de medicamentos e equipamentos hospitalares, etc., e na drenagem da contribuição do trabalhador para sustentar tudo isso. Pois a fonte geradora dos recursos que é o trabalhador, contribui de maneira compulsória, mas não dispõe de qualquer mecanismo de participação nas decisões sobre saúde. É o médico que detém todo o poder sobre a destinação desses recursos, se ja exercendo cargos de direção nas instituições e na política, seja determinando os procedimentos diagnósticos e terapêuticos para o seu paciente, segundo LANDMANN (1982). "Aos olhos do dono do hospital ou da indústria farmacêutica, o médico é o real consumidor. É ele quem gera a renda do hospital, sendo responsável por $80 \%$ dos seus gastos".

0 mesmo autor demonstra que a classe médica tem ignorado a medicina social, permanecendo fiel ao "imperialismo cultural", à tecnologia alienada, à especialização e sofisticação e mesmo aos preconceitos mais absurdos e às práticas eticamente duvidosas, porém muito lucrativas" (LANDMANN, 1982). Não cabe a esse trabalho criticar a contraditória problemática da classe médica, de resto já bastante discutida, mas apenas reconhecer a inegável hegemonia dela no campo de saúde, que determina todo um universo conceitual para todas as outras categorias profissionais que atuam neste campo. Assim é que a Enfermagem mantém to- 
do um currículo "técnico", voltado para o indivíduo isolado, biológico por excelência, seguindo o "modelo ideológico" imposto pela classe médica. É claro que com esse procedimento, ela reforça a dominação da classe médica e sua própria subserviência. Não se pode esquecer que, sendo o médico quem exerce o poder econômico na Saúde, é ele que, em última instância, estabelece o perfil do profissional que será economicamente valorizado. Assim, o "bom Enfermeiro" tem sido o trabalhador "idealista", tarefeiro, fiscalizador, acrítico e apolítico, caso contrário corre o risco de ficar desempregado. Entretanto, já que a classe médica não a quer, por que não preparar a Enfermagem para a Saúde coletiva, a prevenção e promoção da Saúde, que hoje os profissionais não assumem por não terem suficientes conhecimentos? A autonomia da Enfermagem, certamente não é possível no modelo privativista de Saúde, com seus "donos" tradicionais e poderosos. Mas a própria contradição capitalista que impõe o modelo caro, sofisticado e consumista de saúde, leva à falência desse modelo e à busca de soluções para 0 impasse. A conjuntura atual aponta para a impossibilidade econômica da manutenção exclusiva do modelo privativista. A hora da medicina social pode ser a hora da Enfermagem se esta categoria tiver bom senso para não deixar passar o "trem da história", pois é nesse momento que se questiona o modelo de assistência e o profissional que a executa.

\section{- O Alcance Social da Atuação do Enfermeiro}

Foi perguntado: "Em que medida o trabalho do Enfermeiro de Saúde Pública tem contribuido para melhorar o nível de Saúde da população-alvo do posto de saúde onde você trabalha?" com as seguintes opções: contribuindo significativamente, contribuindo razoavelmente, quase não tem contribuido, não tem contribuindo. "Por que?"

Os resultados foram os seguintes:

Contribuindo significativamente -04 ; Contribuindo razoavelmente - 12; Quase não tem contribuido 06 .

Como já está exaustivamente demonstrado, tanto na prática como na ampla bibliografia existente sobre saúde e contexto social, o "nível" de saúde não é afetado pela ação de nenhum profissional isolado ou em equipe, principalmente dentro de um sistema de saúde que apenas of erece um atendimento de má qualidade à doença como o próprio enfermeiro reconheceu nas respostas anteriores deste questionário. Assim sendo, parece incoerente que se afirme que o Enfermeiro tem contribuído "significativamente" e mesmo "razoavelmente", como a maioria fez. Exemplos:

_ "Porque é responsável pela organização do serviço

(juntamente com a chefia), treinamento de pessoal de enfermagem, orientação à comunidade e da qua- lidade do serviço prestado". (Respondeu: contribuindo significativamente...)

- "Devido ao grande esforço do enfermeiro e à importância do seu papel no serviço de saúde pública, ele tem participado ativamente de todos os programas implantados e todas as atividades desenvolvidas no C.S., tentando assim atingir os objetivos". (Respondeu: contribuindo razoavelmente...)

- "Porque a melhoria do nível de saúde da população está estritamente ligado às condições de vida desta população, nas quais os enfermeiros ou qualquer outro profissional de Saúde Pública têm pouquíssimas condições de interferir'. (Respondeu: quase não tem contribuído...)

É interessante observar que nenhum respondeu que seu trabalho não tem contribuído para melhorar o nível de saúde da população, mesmo quando o afirmam na explicação. O alcance social do trabalho do Enfermeiro é nulo, em razão ao próprio contexto onde ele desenvolve sua ação, uma vez que não atinge as estruturas do sistema de produção, não modifica a pirâmide social nem a dominação de uma das classes sobre as outras e 0 antagonismo existente entre elas. 0 nível de saúde da população, historicamente, só tem melhorado, nas sociedades capitalistas, com a maior organização da sociedade e sua capacidade de exercer pressão sobre a estrutura jurídico-política, de forma a permitir uma mais justa distribuição da produção social. Ou seja, quando a pressão exercida pelas classes oprimidas ganha poder de barganha pela ameaça que passa a constituir para a estrutura econômica básica do sistema capitalista. $\mathrm{E}$ isso, na grande maioria das vezes, é o que o trabalho do Enfermeiro ou de qualquer outro "agente de saúde" tenta evitar. Quando prescreve métodos de sobrevivência que são "jeitinhos" de administrar as crises, ou aplica medidas paliativas, ou assume os valores simbólicos como autoritarismo, onipotência, etc., que o sistema lhe atribui para compensálo e mantê-lo cego e manipulável (isto foi o que muitos demonstraram pelas repostas do questinário). Enfim, quando, de qualquer forma, reproduz a dominação ideológica das classes hegemônicas ele não pode melhorar o nível de saúde da população. Pode, quando muito, impedir a si mesmo de engrossar as estatísticas de desemprego. Não se questiona aqui honestidade e competência a nível individual.

A estreiteza de percepção que restringe a unidade de saúde à causa dos problemas sociais e, conseqüentemente, também os meios de resolvê-los, perpassa a grande maioria das respostas junto a uma "justificativa" ou "desculpa" pelo pouco ou muito que o Enfermeiro está contribuindo para melhorar o nível de saúde da população. Não se pode esquecer a difícil luta enfrentada pela Enfermagem para afirmar-se como profissão digna e respeitável. É necessário reconhecer que sua posição é ainda bastante vulnerável apesar da luta de seus profissionais para sair de sua posição su- 
balterna e dominada e conquistar reconhecimento social e valorização econômica. Sabe-se que a validade social e mesmo profissional do Enfermeiro é permanentemente questionada principalmente pelos representantes do capital. Para a lógica da acumulação o Enfermeiro é aquele profissional caro e substituível, sem que essa substituição, com todos os riscos que possa comportar para o paciente, seja sequer percebida pela clientela. É também questionada pela hegemonia médica e o será enquanto esse profissional estiver introjetando os valores simbólicos de sua própria classe que o tornam tão idealmente reprodutor das relações de dominação típicas do capitalismo e enquanto a Enfermagem ameaçar esses valores com suas pretensões a "igualdade". Diante de tudo isso é perfeitamente compreensível que o Enfermeiro queira valorizar a sua prática, reconhecendo nela a importância social que os outros lhe negam. Mas ao fazê-lo de forma ingênua, irrefletida, listando uma série de tarefas, no mínimo socialmente inócuas, ele faz exatamente o contrário do que pretende. A enfermagem não provará o seu valor com discursos alienados e superficiais, mas com conhecimento científico, consciência política e competência técnica.

É preciso ficar claro que o fato de não estar em condições de contribuir para melhorar o nível de vida da população não é "culpa" ou carácterística exclusiva da Enfermagem, mas de todo o sistema econômico brasileiro, do qual o sistema de saúde é conseqüente. Reconhecer isto, não é "desprestígio" para a Enfermagem, mas poderá direcioná-la para uma nova "postura" política, baseada numa permanente busca de soluções não dominadoras, mais esclarecidas e socialmente responsáveis, que acabam por lhe conquistar o reconhecimento social capaz de fortalecê-la como profissão.

A análise clara e explicitamente contida nos do- cumentos que analisam a situação da saúde na América Latina e, principalmente, aqueles que buscam implantar uma mudança da política de saúde no Brasil, é de que o profissional de saúde está inadequado para as solicitações do momento, precisa ser "atualizado" no seu momento histórico, isso não apenas o Enfermeiro, mas todas as categorias profissionais. Talvez se a Enfermagem puder mudar a si mesma sem esperar que os "seus maiores" mudem primeiro, ou lhe dêm permissão para mudar, ela talvez encontre seu "carisma" nesses novos tempos. Ao se abrir para uma maior compreensão da dinâmica social e uma maior participação coletiva, talvez consiga ajudar a conquistar a justiça social e a tornar reais os objetivos éticos dos serviços de saúde que ainda são apenas mascaradores da realidade. $E$ então se poderá dizer que ela tem contribuido "razoavelmente" para melhorar o nível de saúde da população.

\section{A FORMAC̣̃̃O ACADÊMICA DO ENFERMEIRO DE SAÚDE PÚBLICA}

À pergunta: "Você considera que sua formação acadêmica lhe deu as condições necessárias para atuar junto à comunidade?" - obteve-se dois "sim" e vinte "não" - refletindo uma lamentável verdade, limitadora das possibilidades de realização do Enfermeiro de Saúde Pública.

Com exceção de umas poucas respostas, a explicação dada nos questionários conseguiu levantar alguns dos problemas mais gritantes das Escolas de Enfermagem de Belo Horizonte e que, provavelmente, se aplicam a todo o Brasil.

Fica o testemunho dos próprios Enfermeiros para a reflexão dos responsáveis pela formação deste profissional:

\begin{tabular}{|c|c|c|c|}
\hline No & SIM & NÃO & RESPOSTA - (ANO DA FORMATURA) (CURSO) \\
\hline 1 & & $\mathrm{X}$ & $\begin{array}{l}\text { "Porque eu só fui me interessar e conhecer S.P. no curso de Habilitação em S.P. } \\
\text { e, no meu currículo, nem se mencionou trabalhos de atuação com a comunida- } \\
\text { de". (1982) (Habilitação). }\end{array}$ \\
\hline 2 & & $\mathrm{X}$ & $\begin{array}{l}\text { "Porque tive um curso voltado para assistência ao paciente hospitalizado, o que } \\
\text { acho um erro grave em relação às Instituições de Ensino". (1976) (Habilitação } \\
\text { Médico-Cirúrgica). }\end{array}$ \\
\hline 3 & & $\mathrm{X}$ & $\begin{array}{l}\text { "A Escola não prepara o aluno nessa área". } \\
\text { (1979) (Habilitação). }\end{array}$ \\
\hline 4 & $\mathrm{X}$ & & $\begin{array}{l}\text { "Recebe-se subsídios básicos e gerais relevantes". (1979) (Especialização em } \\
\text { Materno-Infantil Un. B.). }\end{array}$ \\
\hline 4 & & $\mathrm{X}$ & $\begin{array}{l}\text { "Não consegui sair da graduação com uma visão do que seria comunidade, to- } \\
\text { das as atividades que me foram dadas a aprender estavam dirigidas ao atendi- } \\
\text { mento do indivíduo, isolado de sua comunidade". (1971) (Especialização). }\end{array}$ \\
\hline
\end{tabular}




\begin{tabular}{|c|c|c|c|}
\hline № & SIM & NÃO & RESPOSTA - (ANO DA FORMATURA) (CURSO) \\
\hline 6 & \multirow{16}{*}{$\mathrm{X}$} & $\mathrm{X}$ & $\begin{array}{l}\text { "Em parte. Do conteúdo programático muito tem a ver, porém a realidade sócio- } \\
\text { econõmica com que nos deparamos dificulta a nossa atuação". (1977) } \\
\text { (Habilitação). }\end{array}$ \\
\hline 7 & & $\mathrm{X}$ & "A prática é muito diferente do que se aprende na Escola". (1979) (Habilitação). \\
\hline 8 & & $\mathrm{X}$ & $\begin{array}{l}\text { "A formação universitária proporcionou pouca consciência política ou social". } \\
\text { (1976) (Habilitação). }\end{array}$ \\
\hline 9 & & $\mathrm{X}$ & $\begin{array}{l}\text { "A teoria sem prática não é válida. E essa prática só é tida no campo, já como } \\
\text { profissional". (1970) (Especialização). }\end{array}$ \\
\hline 10 & & & Não respondeu \\
\hline 11 & & $\mathrm{X}$ & “Me mostrou os caminhos, mas faltaram os subsídios". (1981) (Habilitação). \\
\hline 12 & & $\mathrm{X}$ & $\begin{array}{l}\text { "Faltou maior conhecimento sobre as reais necessidades da comunidade". (do } \\
\text { local do estágio) (1980) (Habilitação). }\end{array}$ \\
\hline 13 & & $\mathrm{X}$ & $\begin{array}{l}\text { "Existe toda uma teoria própria de um trabalho com a comunidade, que não } \\
\text { fez parte da minha formação. Realmente haviam poucos teóricos brasileiros na } \\
\text { época, mas alguns expoentes já existiam e acho que a própria Escola os desco- } \\
\text { nhecia". (1971) (Especialização na USP). }\end{array}$ \\
\hline 14 & & & “'O Curso de Habilitação, principalmente”. (1981) (Habilitação + Especialização). \\
\hline 15 & & $\mathrm{X}$ & $\begin{array}{l}\text { "Algumas condições, sim, mas não o necessário. Na minha época os estágios, is- } \\
\text { to é, a parte prática, era } \pm 95 \% \text { na área hospitalar". (1981) (Especialização ENSP). }\end{array}$ \\
\hline 16 & & $X$ & $\begin{array}{l}\text { "Tive uma formação eminentemente técnica". (1978) (Habilitação + } \\
\text { Especialização). }\end{array}$ \\
\hline 17 & & $X$ & $\begin{array}{l}\text { "Obtém-se a nível acadêmico, uma formação técnica, precária, desligada da rea- } \\
\text { lidade. As Escolas, ao formarem os alunos, parecem desconhecer a realidade so- } \\
\text { cial, econõmica e política do país”. (1976) (Especialização em S.P. e Administra- } \\
\text { ção de Saúde). }\end{array}$ \\
\hline 18 & & $\mathrm{X}$ & $\begin{array}{l}\text { "A comunidade e os trabalhos comunitários, são muito teóricos dentro da Uni- } \\
\text { versidade, não permitindo uma visão real de todo o complexo campo de atua- } \\
\text { ção". (1981) (Habilitação). }\end{array}$ \\
\hline 20 & & $X$ & $\begin{array}{l}\text { "Porque esta formação foi totalmente alienada em relação às condições reais } \\
\text { da população brasileira". (1978) (Habilitação + Especialização). }\end{array}$ \\
\hline 21 & & $\mathrm{X}$ & $\begin{array}{l}\text { "O currículo abrange principalmente a Enfermagem hospitalar, curativa, fican- } \\
\text { do a habilitação de Enfermagem, com o objetivo de formar o Enfermeiro de S.P." } \\
\text { (1978) (Habilitação + Especialização). }\end{array}$ \\
\hline 22 & & $X$ & $\begin{array}{l}\text { "Talvez a Universidade ainda esteja muito presa à especificações de cada pro- } \\
\text { fissão". (1979) (Habilitação). }\end{array}$ \\
\hline
\end{tabular}

\section{CONCLUSÃo}

Este estudo se fez baseado na Enfermagem como prática social e política, que historicamente tem sido: pseudo-neutralidade política, levando ao conservadorismo das relações sociais consequente da alienação. Esta falta de percepção das relaçp̃oes mais amplas que se estabelecem no contexto social, onde o Enfermeiro desenvolve sua ação, limita as possibilidades de um compromisso profissional verdadeiro e eficaz. Tanto a alienação, como a ineficácia do compromisso profissional do Enfermeiro, não podem ser assumidos como "culpa" da Enfermagem, mas serem entendidos à luz da determinação econõmica do modo de produção adotado no Brasil, que impõe ao Enfermeiro um papel específico e condizente com as necessidades de manutenção desse sistema. Por isso, a finalidade última do presente trabalho é ajudar o Enfermeiro a desmascarar os mecanismos controladores de sua atuação, contribuindo para aprofundar sua compreensão sobre si 
mesmo, o significado e alcance social de sua prática, a fim de que ele possa situar-se e, situando-se, orientarse na direção de uma atuação historicamente mais significativa.

Através do questionário repondido perpassam, a par de uma visão às vezes bastante realista da situação dos serviços de saúde, a demonstração da introjeção dos valores simbólicos que a ideologia veicula e a categoria profissional reproduz. A incoerência e a dificuldade de verbalização apontam para a necessidade de aprofundamento da reflexão. Mas também já surgem colocações que indicam que o Enfermeiro começa a tomar consciência dos mecanismos que o manipulam e passa a resistir aos mesmos ocupando, com propósito e consciência, seu espaço intra-sistêmico.

Entre aquelas situações sobre as quais a visão do Enfermeiro se mostra "realista"estão os serviços de Saúde Pública e as Escolas de Enfermagem. Os primeiros definidos como aquela área específica do setor saúde, cujos serviços não são diretamente remunerados pelo usuário, estando a cargo de instituições e serviços públicos politicamente controlados. Sofrem, pois, os ef eitos das pressões das forças políticas que atuam na sociedade, exercendo uma função "equilibradora" ou "compensadora" dos grandes desníveis sociais existentes entre as classes. Realizam, assim, seu papel controlador das tensões sociais. 0 Enfermeiro percebe que, no Brasil, Saúde Pública não quer dizer necessariamente, sanitarismo, estando reduzida a um atendimento $\mathrm{cu}$ rativo e individualizado de baixa renda. As Escolas de Enfermagem, mantendo um currículo onde não são explicitadas nem a determinação, nem a dinãmica das relações sociais, "hospitalista", exclusivamente biológica, voltada para o indivíduo isolado, reproduz, a seu modo, as relações de dominação, produzindo o profissional "certo" para a "função" certa na engrenagem econômica, cuja lógica é a acumulação.

Também perpassam pelas respostas a ansiedade, a insegurança, as sofridas buscas e frustrações e até as "justificativas" com que o Enfermeiro, como ser histórico, ainda que não totalmente crítico, elabora o seu futuro.

Com base em tais resultados pode-se esperar que, no futuro, o Enfermeiro assuma uma consciente e lúcida ação profissional, cujo compromisso político seja com o Homem e não com a dominação e a opressão de qualquer espécie. Ação que vise uma maior participação das pessoas nas decisões que lhes dizem respeito. Que ajude a organização social das camadas populares; que valorize seu conhecimento e a ajude a in- corporar alguns outros; que busque "junto com a comunidade" e não "para a comunidade" as formas de resolver seus problemas de saúde; que entenda suas formas de resistência à dominação e a incentive, tornando-a mais eficaz através da utilização dos mecanismos sociais mais adequados. Para isso o Enfermeiro deverá entender o jogo de forças que atuam socialmente e determinam a direção da política. Ao pretender mudanças ele deverá saber separar o que é estrutural no sistema capitalista do que é conjuntural num dado momento e as manobras que garantem a sobrevivência da estrutura, ao longo das várias conjunturas. Ele deverá preencher seu espaço intra-sistêmico, buscando abrir brechas na estrutura do sistema, por onde possam penetrar as reivindicações populares e seus anseios por saúde. Esta "ação política consequente" só será possível quando Enfermeiro for capaz de situar-se social e historicamente, a fim de poder estabelecer seus objetivos e direcionar-se para eles. Seu compromisso deve abranger ainda sua classe profissional, que tem tido, pelas suas características próprias pouca expressividade política, o que não lhe dá condições de pressionar convenientemente o sistema para obter respostas expressivas. Enfim, ela dispõe de pequeno poder de barganha, o que a torna frequentemente negligenciada pelo setor político, como categoria profissional com baixo nível de organização. Assim, sua ação política deve direcioná-la também para formas mais organizadas de participação nos órgãos de classe como Sindicatos, COREn, ABEn, etc.

\section{REFERÊNCIAS BIBLIOGRÁFICAS}

1. BRASIL, Ministério da Previdência e Assistência Social MPAS/CONASP. Plano de reorganização da assistência à saúde no ãmbito da Previdência Social. 1982. Mimeogr.

2. CAMPOS, Juarez de Queiroz. Planejamento de saúde. Apostila da UNAERP. Mimeogr.

3. FREIRE, Paulo. Educação e Mudança. 2. ed., Rio de Janeiro, Paz e Terra, 1979.

4. GEBRAN, Philomena et alii. Conceito de Modo de Produção. Rio de Janeiro, Paz e Terra, 1978.

5. LANDMANN, Jayme. Evitando a saúde e promovendo a doença. Sistema de Saúde no Brasil. 3. ed. Rio de Janeiro, Achiamé, 1982.

6. REZENDE, Ana Lúcia Magela de. Contribuição para uma análise histórica do pensare do fazer nas açōes de Enfermagem. Uma visão não dicotômica da formação acadêmica do Enfermeiro. São Paulo. USP, Faculdade de Educaçp̄ao. Tese mestr.

7. SAÚDE EM DEBATE. Por uma política democrática de saúde. São Paulo, CEBES n. 17, jul. 1985. Edição especial. 